\title{
Yksilöllinen ja ryhmälopetus tarhatulla minkillä
}

\author{
Hannu T. Korhonen, Pekka Eskeli, Juhani Sepponen
}

MTT, Kotieläintieteen laitos, 69100 Kannus, hannu.t.korhonen (at)mtt.fi

\section{Tiivistelmä}

Eläinten hyvinvointi lopetuksen yhteydessä on hyvin tärkeää. Tämän tutkimuksen tarkoituksena oli selvittää yksilöllinen ja ryhmälopetuksen tehokkuutta tarhatulla minkillä (Neovison vison). Tutkitut kaasut olivat: koneellinen häkä $(\mathrm{CO})$, pullotettu häkä $(\mathrm{CO})$ ja pullotettu hiilidioksidi $\left(\mathrm{CO}_{2}\right)$. Kaasujen toimivuutta tutkittiin neljällä erilaisella koeasetelmalla: (1) yksilöllinen lopetus pienessä lopetuslaatikossa (35 x 30 x 60 $\mathrm{cm}$; korkeus x leveys x pituus) ilman killeriä; (2) yksilöllinen lopetus pienessä lopetuslaatikossa, sisällä killeri (12.5 x 12.5 x $55 \mathrm{~cm}$; korkeus x leveys x pituus ); (3) ryhmälopetus suuressa lopetuslaatikossa (75 x $75 \times 150 \mathrm{~cm}$; korkeus x leveys x pituus); and (4) ryhmälopetus suuressa lopetuslaatikossa (70 x $70 \times 125$ $\mathrm{cm}$; korkeus $\mathrm{x}$ leveys $\mathrm{x}$ pituus). Yksilöllisessä lopetuksessa koneellinen häkä jonka pitoisuus oli 1.2-3\% osoittautui liian alhaiseksi. Minkki ei joko kuollut lainkaan tai se kuoli hyvin hitaasti (>7-15 minuuttia). Pitoisuudet välillä 4-6\% olivat tehokkaita tappamaan eläimen kivuttomasti 3-6 minuutin kuluessa kaasutuksen aloittamisesta. Koneellisella ja pullotetulla häällä eläimen kuolinaika oli suurin piirtein sama. Hiilidioksidipitoisuus $\geq 80 \%$ oli tehokas tappamaan eläimen nopeasti, 4-5 minuutin kuluessa. Hiilidioksidi oli hieman tehokkaampi kuin häkä. Ryhmälopetuksessa ensimmäinen eläin kuoli nopeimmin hiilidioksidilla $\left(\mathrm{CO}_{2}\right.$ vs pullotettu $\mathrm{CO} ; \mathrm{P}=0.0045 ; \mathrm{ja} \mathrm{CO}_{2}$ vs koneellinen $\left.\mathrm{CO} ; \mathrm{P}=0.0009\right)$. Pullotetun ja koneellisen hään välillä ei ollut tilastollista eroa $(\mathrm{P}=0.4654)$. Tulokset osoittavat selkeästi, että häkäpitoisuus $\geq 4 \%$ ja hiilidioksidipitoisuus $\geq 80 \%$ ovat tehokkaita tarhatun minkin lopetuksessa. Sekä pullotettuja että koneella tuotettuja kaasuja voidaan siis käyttää. Tutkittujen kaasujen $\left(\mathrm{CO}, \mathrm{CO}_{2}\right)$ ei havaittu aiheuttavan ärsytystä tai levottomuutta minkeille. Riittävä eläinten hyvinvointi voidaan taata tutkituilla kaasuilla kunhan niitä käytetään oikein.

Asiasanat: Turkiseläintuotanto, hyvinvointi, minkin lopetus

\section{Johdanto}

Eläimet kykenevät tuntemaan niin positiivisia kuin negatiivisiakin tuntemuksia. Tämän vuoksi ihmisillä on velvollisuus huolehtia eläinten hyvinvoinnista aina niiden kuolemaan saakka. Eläinten hyvinvointi on arvo, joka on vahvistettu Euroopan yhteisön perustamissopimukseen liitetyssä pöytäkirjassa (N:o 33). Turkiseläinten hyvinvointi ja kohtelu herättää suurta yhteiskunnallista kiinnostusta ja keskustelua. Kaikki eläimiä käsittelevät tahot ovat vastuussa eläinten hyvinvoinnista ja hyvästä kohtelusta.

Eläinten hyvinvointi lopetuksen yhteydessä on hyvin tärkeää. Lopetuksella tarkoitetaan tarkoituksella tehtyä toimenpidettä, jonka seurauksena eläin kuolee. Voimassaolevien asetusten yhteydessä voidaan lopetuksen kuitenkin käsittää tarkoittavan hyvän kuoleman tuottamista eläimelle, sillä Euroopan neuvoston asetuksen (EY) N:o 1099/2009 tarkoituksena on vähentää kipua, tuskaa ja kärsimystä lopetuksen ja siihen liittyvien toimenpiteiden aikana (Korhonen \& Huuki, 2012a,b; Korhonen \& Eskeli, 2012).

Tämän tutkimuksen tarkoituksena oli selvittää yksilöllinen ja ryhmälopetuksen tehokkuutta ja toimivuutta tarhatulla minkillä (Neovison vison). Erityisesti eläinten hyvinvointiin kiinnitettiin huomiota. 


\section{Aineisto ja menetelmät}

Neljä ryhmää dark urosminkkejä testattiin seuraavasti: lopetus pakokaasulla ( $\mathrm{CO} \geq 4 \%, 8$ eläintä), lopetus hiilidioksidilla $\left(\mathrm{CO}_{2}\right.$ pullosta, $99.5 \%$ pitoisuus, 8 eläintä), hiilimonoksidilla (CO pullosta, $4 \%$ pitoisuus, 9 eläintä) ja lopetus hiilimonoksidilla (CO pullosta, 2\% pitoisuus, 6 eläintä). Aivorungon aktiivisuus (Brainstem auditory evoked responses, BAER), aivosähkökäyrä (EEG), sydänkäyrä (ECG) sekä hengitystiheys mitattiin ennen lopetusta ja eutanasian aikana. Minkin lopetuskoe isoissa ryhmissä käyttäen lopetuksessa laatikkoa kooltaan 150 x 75 x $75 \mathrm{~cm}$ (pituus x korkeus x leveys) tehtiin marraskuussa .

Laatikkoon rakennettiin pleksi-ikkunat kahdelle sivulle sekä kattoon. Laatikkoon sopii enimmillään 75 urosta ja 75 naarasta yhtä aikaa. Kyseistä lopetuslaatikkomallia käytetään tarhoilla yleisesti maassamme. Kokeessa käytimme laatikossa 30-35 minkkiä per lopetuskerta. Laatikkoon oli sijoitettu sisälle mikrofoni (Olympus VN-6800PC Digital Voice Recorder China) joka tallensi eläinten ääntelyn. Laatikkoa kuvattiin sisältä kahdella kameralla (Canon Digital Camrecorder MV-900; Samsung FullHD BSI, China) molemmista pitkittäisistä päistä. $\mathrm{CO}_{2}$-pitoisuus mitattiin DAT-2 Special Tiedonkeruu-mittarilla (Pietiko Oy, Turku). COpitoisuus mitattiin oheisella laitteella: BINOS 1, $\mathrm{CO}$ and $\mathrm{CO}_{2}$ analyzer, Leybold-Heraeus, Germany.

Yksityiskohtaiset tiedot aineistosta ja menetelmistä löytyvät julkaisuista Korhonen et al. 2012 ja Korhonen et al. 2013a.

\section{Tulokset ja tulosten tarkastelu}

Taulukko 1. Yhteenveto elektrofysiologisista tuloksista. EEG=aivosähkökäyrä. BAER=aivorungon aktiivisuus, ECG=sydänsähkökäyrä. Tulokset sekunteina kaasutuksen alusta. Kirjaimet a-c tarkoittavat tilastollista eroa $(\mathrm{P}<0.05)$ ryhmien (kaasulähteiden) välillä. Tilastollinen analyysi: Kruskal-Wallis ANOVA.

\begin{tabular}{|l|c|c|c|c|}
\hline \multirow{2}{*}{ Ryhmä } & \multicolumn{2}{|c|}{ EEG } & \multicolumn{2}{c|}{ BAER } \\
\cline { 2 - 5 } & Normaali & Poissa & Normaali & Poissa \\
\hline Pakokaasu & $42 \pm 10^{\mathrm{a}}$ & $86 \pm 35^{\mathrm{ab}}$ & $63 \pm 19^{\mathrm{ab}}$ & $176 \pm 37^{\mathrm{a}}$ \\
\hline $\mathrm{CO}_{2}$ & $39 \pm 10^{\mathrm{a}}$ & $75 \pm 28^{\mathrm{a}}$ & $45 \pm 16^{\mathrm{a}}$ & $183 \pm 19^{\mathrm{ab}}$ \\
\hline $\mathrm{CO} 4 \%$ & $55 \pm 11^{\mathrm{ab}}$ & $190 \pm 81 \mathrm{~b}^{\mathrm{c}}$ & $143 \pm 70^{\mathrm{bc}}$ & $390 \pm 139 \mathrm{bc}$ \\
\hline $\mathrm{CO} 2 \%$ & $176 \pm 126^{\mathrm{b}}$ & $426 \pm 252^{\mathrm{c}}$ & $305 \pm 148^{\mathrm{c}}$ & $833 \pm 345^{\mathrm{c}}$ \\
\hline $\mathrm{P}_{\text {ryhmä }}$ & $<0.01$ & $<0.0001$ & $<0.0001$ & $<0.0001$ \\
\hline
\end{tabular}

\begin{tabular}{|l|c|c|c|c|}
\hline \multirow{2}{*}{ Ryhmä } & \multicolumn{2}{|c|}{ Hengitys } & \multicolumn{2}{c|}{ ECG } \\
\cline { 2 - 5 } & Normaali & Poissa & Normaali & Poissa \\
\hline Pakokaasu & $42 \pm 17^{\mathrm{ab}}$ & $217 \pm 53^{\mathrm{a}}$ & $105 \pm 37^{\mathrm{a}}$ & $292 \pm 130^{\mathrm{ab}}$ \\
\hline $\mathrm{CO}_{2}$ & $28 \pm 5^{\mathrm{a}}$ & $227 \pm 26^{\mathrm{a}}$ & $117 \pm 31^{\mathrm{a}}$ & $220 \pm 92^{\mathrm{a}}$ \\
\hline $\mathrm{CO} 4 \%$ & $144 \pm 67^{\mathrm{bc}}$ & $477 \pm 151^{\mathrm{b}}$ & $219 \pm 100^{\mathrm{ab}}$ & $289 \pm 126^{\mathrm{ab}}$ \\
\hline $\mathrm{CO} 2 \%$ & $331 \pm 191^{\mathrm{c}}$ & $901 \pm 293^{\mathrm{b}}$ & $481 \pm 184^{\mathrm{b}}$ & $682 \pm 333^{\mathrm{b}}$ \\
\hline $\mathrm{P}_{\text {ryhmä }}$ & $<0.0001$ & $<0.0001$ & $<0.001$ & $<0.01$ \\
\hline
\end{tabular}


Yhteenveto tuloksista on nähtävissä taulukossa 1. Keskimääräinen aika jolloin BAER väheni/katosi oli 112/176, 138/183, 235/390 ja 528/833 sekuntia kaasutuksen alkamisesta eri ryhmissä. Keskimääräinen aika jolloin EEG muuttui/katosi oli 42/86, 39/75, 55/190 ja 176/426 sekuntia. Keskimääräinen aika ensimmäisiin muutoksiin/ katoamiseen hengityksen osalta oli 42/217, 28/227, 144/477 ja 331/901 sekuntia. Keskimääräinen aika muutoksiin/ katoamiseen ECG:n osalta oli 105/292, 117/220, 215/289 ja 481/682 sekuntia kaasutuksen alusta.

Tulokset indikoivat että tutkitut kaasut vaikuttavat ensin aivoihin ja aivonrungon aktiviteettiin mikä näkyy EEG:n ja BAER:n katoamisena. Koska herkkyys kivulle on erityisesti suhteessa tietoisuuteen ja aivojen toimintaan, niin voidaan katsoa tutkittujen kaasujen tehokkaasti ja ensisijaisesti johtavan kivuttomaan tilaan. Parhaimmaksi menetelmäksi eläimen kannalta osoittautui pullotettu $\mathrm{CO}_{2}$.

Kaasut eivät toimi välttämättä aivan samoin ryhmälopetuksessa kuin yksilölopetuksessa. Lopetus pullotetulla CO:lla näyttää toimivan hyvin; se on käyttövarma, nopea ja tehokas. Siinä on huomioitava kuitenkin käyttöturvallisuus. $\mathrm{CO}_{2}$-pullolopetus ei välttämättä toimi ryhmässä niin hyvin kuin yksilölopetuksessa. Ongelmana oli sekä kaasupullon että hanan jäätyminen pitempiaikaisessa käytössä. Hana on halkaisijaltaan liian pieni. Ilman hanaa $\mathrm{CO}_{2}$-kaasutus onnistui paremmin. $\mathrm{CO}_{2}$-menetelmä kaipaa lisää teknistä kehittelyä. Ryhmälopetuksessa pullotettu $\mathrm{CO}_{2}$ osoittautui tehokkaimmaksi. Pakokaasulla tuotettu häkä ja pullotettu häkä olivat yhtä tehokkaita (Kuva 1).

Kuva 1. Aika (sekuntteja) joka meni minkkien kuolemaan isossa ryhmässä ( $N=18$ urosta, $\mathrm{N}=16$ naarasta). $\mathrm{CO}=$ pakokaasulla tuotettu häkä. $\mathrm{CylCO}=$ pullotettu $\mathrm{CO}, \mathrm{CylCO}_{2}=$ pullotettu $\mathrm{CO}_{2}$. Ajan laskeminen alkoi siitä kun ensimmäinen eläin laitettiin kammioon, ja päättyi siihen kun viimeinen eläin oli kuollut.

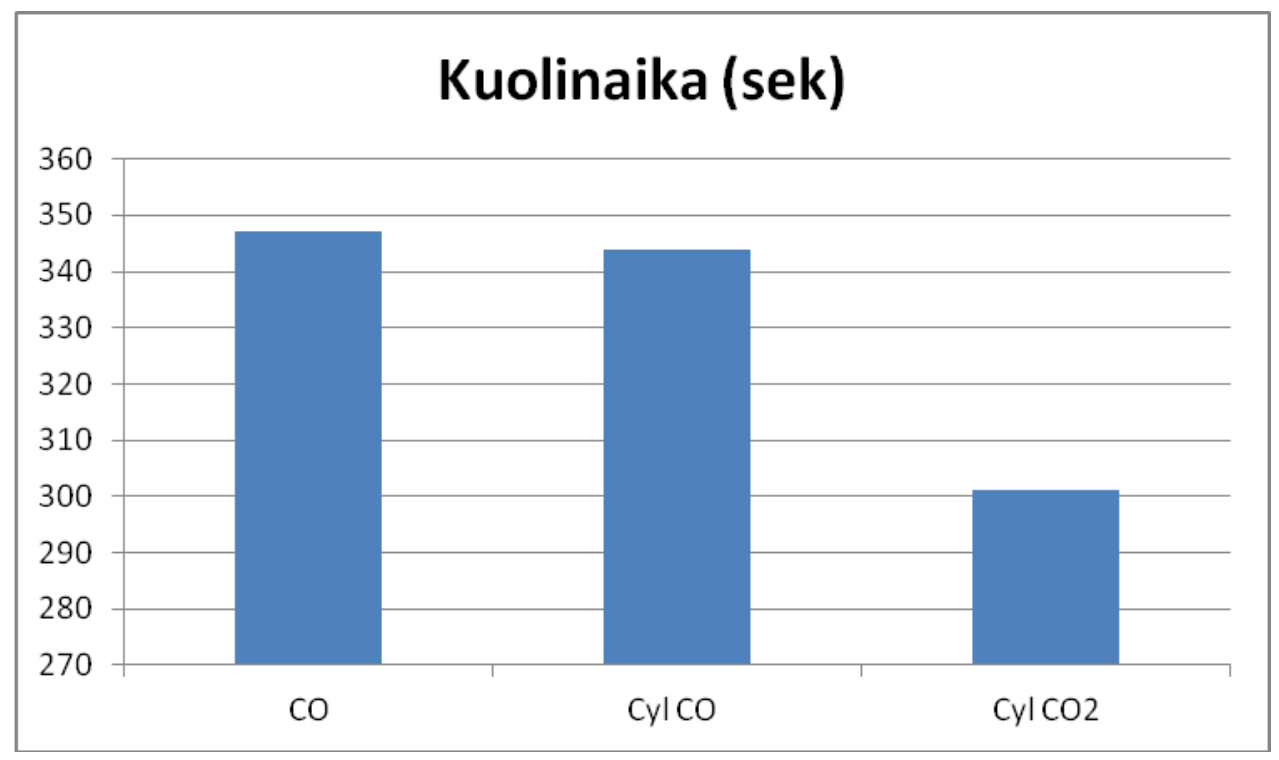

Kaikkien turkistilalla toimijoiden on laadittava toimintaohjeistot, noudatettava niitä, sekä suoritettava omavalvontaa lopetuksen onnistumisesta (Korhonen \& Huuki, 2012a,b). Toimintaohjeiston tarkoitus on yhdenmukaistaa lopetuksessa käytettyjä menetelmiä ja käytäntöjä, ja sitä kautta parantaa eläinten hyvinvointia ja tuottajien kilpailukykyä markkinoilla. Toimintaohjeistossa tulee asettaa tavoitteet, määritellä 
keskeiset valvottavat parametrit ja toimintaohjeet, sekä ohjeet tilanteisiin, joissa eläimen tainnutus syystä tai toisesta ei onnistu oletetusti. Toimintaohjeistoa laadittaessa on myös huomioitava lopetuslaitteen valmistajan ohjeet ja suositukset, jotka lopetusasetus on velvoittanut antamaan. Lopetuslaite on huollettava ja tarkastettava säännöllisesti. Erityisesti tätä tarkoitusta varten koulutetut henkilöt pitävät kunnossa ja tarkastavat kaikki laitteistot valmistajan ohjeiden mukaisesti. Kunnossapidosta tehtävää kirjanpitoa on säilytettävä vähintään vuoden ajan. Kyselytutkimus (Korhonen et al. 2013b) osoitti, että Hollannissa minkin lopetukseen käytetään ainoastaan pullotettua CO:ta. Suomessa ko. menetelmä ei ole käytössä vaan minkit lopetetaan joko koneellisella CO:lla (ruokintatrukki, muu moottori) tai pullotetulla $\mathrm{CO}_{2}$ :lla. Koneellinen $\mathrm{CO}$ on selvästi yleisempi (75.3\% turkistiloista käyttää). Pullotetun $\mathrm{CO}_{2}$ käyttö on lisääntymässä maassamme. Kaikki kolme menetelmää näyttävät toimivan melko hyvin. Ne on sopeutettu kunkin maan olosuhteisiin ja tarpeisiin. Tarhaajat eivät ole kokeneet suurempia terveydellisiä ongelmia kaasujen käytöstä.

Elektrofysiologiset tulokset osoittavat, että tutkitut kaasut vaikuttavat ensin aivoihin ja aivonrungon aktiviteettiin mikä näkyy EEG:n ja BAER:n katoamisena. Koska herkkyys kivulle on erityisesti suhteessa tietoisuuteen ja aivojen toimintaan, niin voidaan katsoa niiden tehokkaasti ja ensisijaisesti johtavan kivuttomaan tilaan. $\mathrm{CO}$ ja $\mathrm{CO}_{2}$ soveltuvat minkin lopetukseen. Ryhmälopetuksessa pullotettu $\mathrm{CO}_{2}$ osoittautui tehokkaimmaksi. Pakokaasulla tuotettu häkä ja pullotettu häkä olivat yhtä tehokkaita surmaamaan ryhmässä lopetetut minkit.

Tutkimusten avulla saatiin ne tulokset joita tarvittiin hyvän toimintatavan oppaan laatimiseen. Tutkimustulokset on julkaistu raportteina, tieteellisinä artikkeleina, seminaariesitelminä sekä ammattilehtikirjoituksina. Lisäksi tuloksia on esitelty tieteellisissä kongresseissa ja seminaareissa sekä muissa elinkeinon tilaisuuksissa. Tulokset ovat tieteellisesti merkittäviä. Tulokset ovat erittäin merkittäviä myös käytännön kannalta. Käytettävät lopetusmenetelmät ovat toimivia ja takaavat riittävän eläinten hyvinvoinnin oikein käytettynä. Tulosten perusteella laadittiin hyvän toimintatavan opas minkin lopetukseen (Korhonen \& Huuki, 2012a). Opas on käytössä koko Euroopan alueella (Korhonen \& Huuki, 2012b).

\section{Johtopäätökset}

Eläinten hyvinvointi lopetuksen yhteydessä on hyvin tärkeää. Uusi Euroopan neuvoston asetus lopetuksesta koskee myös turkiseläimiä. Lain soveltamiseksi on tehty runsaasti tutkimustyötä niin ketuilla kuin minkilläkin. Nyt tiedetään tarkasti miten kuolinprosessi fysiologisesti etenee ja mitä eläimelle missäkin vaiheessa tapahtuu. Minkit lopetetaan yleisimmin kaasulla, joko hiilimonoksidilla tai hiilidioksidilla. Tehokas kaasulopetus edellyttää, että lopetuskammiossa on riittävä kaasupitoisuus ennen kuin eläin laitetaan kammioon. Kaasut vaikuttavat ensin eläimen aivoihin. Eläimeltä katoaa tietoisuus ja kipuaistimuskyky, lopulta siitä tulee aivokuollut. Oikein käytettynä kaasulopetus on kivuton ja eettinen menetelmä.

\section{Kirjallisuus}

Korhonen, H.T., Cizinauskas, S. \& Jesernics, J. 2012. Electrophysiological study on $\mathrm{CO}$ and $\mathrm{CO}_{2}$ euthanasia in mink (Mustela vison). Ann. Anim. Sci. 12(4): 597-608.

Korhonen, H. T. \& Huuki, H. 2012a. Hyvän toimintatavan opas minkin lopetukseen. MTT 7.5.2012. 37 s. Korhonen, H.T. \& Huuki, H. 2012b. Code of good practice for $\mathrm{CO}$ and $\mathrm{CO}_{2}$ euthanasia in mink. MTT. May 15.2012. $28 \mathrm{~s}$.

Korhonen, H.T. \& Eskeli, P. 2012. Minkin lopetus kaasulla - mitä tapahtuu ja miksi? Turkistalous 82 (2): 34-35.

Korhonen, H.T., Eskeli, P., Sepponen, J.\& Toikkanen, P. 2013a. Individual and group euthanasia in farmed mink. Ann. Anim. sci. 13(3): 623-632.

Korhonen, H.T., Sepponen, J. \& Eskeli, P. 2013b. A questionnaire study on euthanasia in farm-raised mink. Educare 5(2): 241-250. 